DOI: $10.20472 / S S .2016 .5 .4 .003$

\title{
TOWARDS A SYNERGETIC AND PROBABILISTIC APPROACH TO CROSS-BORDER MIGRATION
}

\section{NIKOLAI GENOV}

\begin{abstract}
:
The cross-border migration has multiple causes, variety of manifestations and potentials for diverging effects. Paradoxically, the mainstream theories on the phenomenon are one-dimensional and deterministic. The effort to resolve the contradiction proceeds in four steps. First, mainstream theories of international migration are scrutinized for potential contributions to a synergetic and probabilistic conceptual framework. Second, the strategy for building the framework is outlined by elaborating on the components of the migration chain. Third, the components are integrated in a conceptual whole reflecting the multidimensionality and the variability of the migration's structures and processes. Fourth, the capacities of the integrated framework to guide synergetic and probabilistic descriptions, explanations and forecasting of cross-border migration are put under scrutiny. The conceptual developments are tested with a view to the needs for efficient management of the cross-border migration flows.
\end{abstract}

\section{Keywords:}

Cross-border migration; Migration theories; Synergy of concepts; Probabilistic approach; Migration management.

JEL Classification: F22, A14, E24

\section{Authors:}

NIKOLAI GENOV, Prof. em. Free University Berlin, Germany, Email: genov@zedat.fu-berlin.de

\section{Citation:}

NIKOLAI GENOV (2016). Towards a Synergetic and Probabilistic Approach to Cross-border Migration . International Journal of Social Sciences, Vol. V(4), pp. 44-66., 10.20472/SS.2016.5.4.003 


\section{Introduction}

The recent confusing experience of European countries and the European Union in (mis)managing the massive cross-border migration sent a clear message to decisionmakers and social scientists alike: the phenomenon is getting increasingly relevant but more and more difficult to cope with (Luft, 2016; Kingsley, 2016). Consequently, the efforts to design and apply efficient policies for managing cross-border migration are bound to become more intensive and sophisticated. The reasons are numerous. The cross-border migration is inherently related to profound economic, political, legal and moral problems in all affected locations and with regard to all involved actors (Waldinger, 2015; Bauman, 2016). In particular, there are growing concerns about possible impacts of the mass cross-border migration on the domestic and international security (Jansen, Celikates and Bloois, 2015; Bossong and Carrapiço, 2016). Therefore, the practical challenges are multidimensional since mass crossborder migration has multiple causes, large variety of changeable manifestations and diverse effects which are rather difficult to predict precisely.

In a sharp contrast to this complex and probabilistic problem situation one may notice that the mainstream theories on cross-border migration are one-dimensional and deterministic as a rule. Consequently, the design and the application of policy scenarios for the management of cross-border migration are typically based on incompatible, one-dimensional and deterministic concepts. The major reason for the incompatibility is that the conceptual schemes in use are imbedded in the tradition of one or another scientific discipline or in the conceptual framework of one or another influential theoretician. The empirical studies guided by these disconnected conceptual schemes are focused on specific actors, structural levels or processes in the cross-border migration flows. Given this dissatisfactory theoretical and methodological situation one might be even more surprised by the efforts to handle the problem. Their aim is typically not the conceptual synthesis but the establishing of communication channels between the disciplines dealing with cross-border migration (Brettel and Holifield, 2011).

The disparity between the magnitude of the cognitive problem and the strategies for coping with it cannot be acceptable any more. It has been already recognized that reliable descriptions, explanations and forecasting of cross-border migration cannot be achieved by using the conceptual resources of single scientific disciplines or by focusing on the communication between social science disciplines (Favell, 2011). Path-breaking works aiming at a new synergetic conceptual framework are needed. It would be expected to synthesize a variety of so far disconnected theoretical assumptions and perspectives. Bodvarsson and Van den Berg (2013: 27) have recently formulated the task in adequate terms:

The greatest challenge to migration theorists is the organization of all hypothetically relevant factors into one coherent theoretical framework that will specify their interaction with each other in empirically testable form and thereby serve as a guide to future research. 
Therefore, the optimal outcome of the desirable conceptual synthesis is expected to be the well-coordinated multi-dimensional approach to the cross-border migration. The approach has to link structures and processes in the societies of origin with structures and processes in the societies hosting migrants. In addition, the desirable multi-dimensional approach has to pay due attention to the actors and processes connecting the countries of out-migration and immigration.

The comprehensive conceptual framework for the study and management of international migration will have to rely on available "building blocks". The concepts of "push" and "pull" factors of migration belong to them. Both of them are currently suspicious since they can be easily presented as too rationalistic (Brettel and Holifield, 2011: 4). However, provided they would be explicitly and consequently elaborated in the context of the theoretical ideas about needs satisfaction / dissatisfaction (Maslow, 2006) the "push" and "pull" concepts can be efficiently revitalized. They could make their comeback to the core of the interdisciplinary theorizing and empirical research on cross-border migration since the push-pull conceptual framework can allow the systematic inter-connection of the variety of factors determining the cross-border migration. In this way the conceptual framework could incorporate the fluctuations in the intensity of the impacts of specific factors on migration.

Other useful ideas for resolving the task can be obtained from the comparative analysis of currently most often used theories (Massey et al, 2005; Castles, de Haas and Miller, 2014: 25f.). The analysis will not go into details since the critical overview is only intended to be a brief introduction to the development of the suggested synergetic and probabilistic conceptual framework. Its aim is to incorporate a multidimensional strategy for systematic descriptions, explanations and forecasting of cross-border labor migration as a background for successful management strategies and practices. The analysis and argumentation are particularly focused on labor migration. The choice is due to the fact that the work permit and the occupational position in the host country belong to the most desirable achievements of the vast majority of immigrants (Adukule, 2016).

\section{Preparing the Conceptual Move Forward}

The following sketchy analysis cannot do justice many valuable ideas in the theories under scrutiny or pay detailed attention to some important flaws in their theoretical logic, operationalization or applications. The critical overview will only focus on ideas related to the labor migration which is guided by the intention of migrants to obtain labor permit and permanent residence in the host country.

The neoclassical economic theory is the most typical explanatory tool used in the studies on causes, processes and effects of the cross-border labor migration. The core of the theory is based on respectable empirical evidence. There is no doubt that the level of salaries and wages as well as other conditions of employment vary from country to country. Residents of less affluent societies might be motivated to take the risks and to cover the costs of migration to societies with better conditions of work 
and higher salaries and wages. If many so motivated individuals decide to migrate, then the supply of labor in the societies of origin of the migrants would decline. The supply of labor in the better-to-do societies hosting the cross-border migrants would increase. The tentative balance of supply and demand of labor can be restored by changes in the local levels of salaries and wages. They would tend to increase in the countries of origin of the migrants and to decline in their host countries. This macroeconomic effect comes about as an outcome of decisions and actions of individuals trying to increase their human capital. Therefore, individuals are the major factor of the spontaneous societal change due to their personal investment of efforts, time and money in the move from lower income to higher income countries (Borjas, 1989).

As persuasive as it might be at the first glance, the neoclassical economic theory of cross-border migration faces fundamental questions concerning its explanatory potentials. The reason is the mixture of sound and unrealistic assumptions in the fundaments of the theory. It relies on the vision about liberal regimes of border crossing accompanied by the vision of liberal regimes of labor markets. The impressive fence guarding the liberal US American national labor market from the inflow of Latin American labor migrants is one of the telling falsifications of the assumption about the liberal regimes of border crossing. The recent rapid turn of European policies concerning migration from the humanistic principles of "everybody welcome" to the restoration of guarded borders is another clear repudiation of basic neoliberal ideas. As to the supposed liberal labor markets, the conditions in the host countries of cross-border migration typically deviate from the assumption about free access to occupational positions. Labor markets in affluent societies are tightly regulated by national laws and international agreements. The regulations concern the access to the labor market (work permit) and the related issues of wages, taxation, welfare benefits, etc. Official regulations or unwritten habits aim at discouraging migrants to move to the affluent societies or have this effect in practice. The difference between the level of unemployment of the EU born young people 15-29 and the non-EU born young people is the evidence of such effects. In 2015 the unemployment rate among the EU-born young people was $15.7 \%$. The non-EU born young people in the EU had unemployment rate of 26.9\% (Eurostat, 2016). Regulations are often intended to attract only segments of the migration flows. This applies for the efforts to attract only well-educated and trained immigrants, for instance.

Therefore, the neoclassical economic theory of cross-border migration offers some relevant clues for understanding the moving forces of the migration flows. But the theory fails to offer reliable explanations of the causes, processes and effects of the cross-border labor migration because of the unrealistic neoliberal assumptions in its core. Moreover, the theory deals with constructive cases of migration alone and fully neglects the large variety of cases of destructive impacts of cross-border migration on individuals, communities and societies. Millions of immigrants have experienced not enrichment but destruction of their human capital due to the economic pressure to take occupational positions requiring lower education and skills than these they have acquired in their country of origin. 
Given the global advancements of individualization it is refreshing to pay attention to the new economics of migration (Abreu, 2012). It starts from the realistic idea that decisions for cross-border migration are not always taken by individuals alone. The decision-maker might be a collective. The collective decision to send members of the family or the settlement community to work abroad can be taken by considering various circumstances. Under the conditions of a family or settlement community struggling for survival the guiding idea might be the increase of collective's aggregated income. Under conditions allowing relative affluence the collective's decision might be guided by the strategy to diversify the sources of its income.

This conceptual framing of the new economics of migration came about as "grounded theory" resulting from empirical studies on economically underdeveloped rural communities. As many other "grounded theories" this one certainly has explanatory power under specific local contexts of out-migration. But neither its guiding idea nor the suggested explanatory model could be regarded as a generalizable theory. The major limitation is the accelerating global individualization. It causes an increasing replacement of the collective patterns of decision-making by the autonomous orientation, decision and practical action of individuals. The rising educational level of individuals strengthens their capacities to competently take decisions and to act autonomously in cross-border migration (Genov, 2015). Given this context the theoretical model of the new economics of migration is less and less applicable in systematic descriptions and explanations of cross-border migration. Nevertheless, some ideas about collective decision-making concerning migration can be incorporated in the synergetic and probabilistic conceptual schemes explaininbg the international outsourcing of production lines, for instance (Yomogida and Zhao, 2010).

The dual labor market theory takes it for granted that the crucial moving factor of cross-border migration is the structural division between high quality jobs and low quality jobs in the economically advanced societies. The high quality jobs require investments of employers and employees in education and training. In return these jobs are relatively well paid and safe in times of economic stagnation or recession. The low quality jobs are labor intensive and low paid. They are the first to be reduced in times of economic troubles. The low quality occupational positions are not attractive for the native labor force. They tend to be predominantly filled in by low educated and trained immigrants. Some of them do their best to move out of the low quality jobs to better paid positions in the occupational structure. Thus the need to fill in the low quality occupational positions by new immigrants becomes permanent (Saint-Paul, 1996).

The key ideas of the dual labor market theory correspond to some structures and processes of labor markets in the advanced societies. However, the theory totally neglects key components of the cross-border migration like the variety of causes of out-migration and the issues of the move of migrants from the countries of origin to the host country. Moreover, there is nothing like a strict polar division between the high quality capital intensive jobs and the low quality labor intensive jobs in the occupational reality of advanced societies. There are numerous intermediary levels in 
the wide range of occupational positions between the status of top level CEOs and the positions of low educated and low paid manual workers. All these occupational positions can be potentially filled in by migrants since some of them possess valuable cognitive competences, skills and creativity. All written and non-written restrictions in the labor market notwithstanding, the international competition for high quality occupational positions is open for immigrants too. The "head-hunting" departments of big companies are busy searching for the best and brightest in the global labor market for top researchers or managers (Hofmann, 2011). On their part, international migrants are motivated by the attractiveness of the whole range of occupational positions worldwide. Numerous medical doctors trained in India, Pakistan or Nigeria but employed in British hospitals properly illustrate the complexity and the relevance of the situation. The very high share of 41.6 percent of persons with doctorate who were occupied in the US science and engineering sector in 2009 was born outside of the United States (Franzoni, Scelatto and Stephan, 2012: 3). Thus the reality of the labor market questions basic ideas of the dual labor market theory. Nevertheless, it sensitizes researchers about important dimensions of the motivation and selection mechanisms in the labor force recruitment and realization. These mechanisms should be considered and included in the multidimensional research strategy for the study of cross-border migration.

When analyzed in comparative perspective the world system theory offers a rather general approach to international migration. The key idea of the theory is that international migration should be understood as a process determined by the changing centers of global economic power. Currently the economy of the United States and the advanced countries affiliated with it is defined as the center of the world system. The rest of the world is regarded as consisting of subsystems of countries which belong either to the global economic and political semi-periphery or to the global periphery. In this systemic context the major direction of the global flow of sophisticated goods and services as well as of capital comes from the center of the world system and moves towards the global semi-periphery and periphery. The mainstream of international migration of labor is regarded as a parallel flow but in the opposite direction (Hatton and Williamson, 2005).

It is true that the major migration flows move from the so distinguished periphery and semi-periphery to the core of the present-day world system. However, this is a rather general statement. The systematic descriptions and explanations of cross-border migration would require a lot of complimentary concepts covering institutional arrangements and micro-social processes of orientation, decision, action and personto-person networks. These complementary concepts and the related indicators could make the empirical application of the general ideas of the world system theory possible indeed. It is not by chance that only few attempts at achieving testable empirical results by using operationalized concepts of the world-systems theory can be identified (Massey and Espinosa, 1997). Another reason for the few empirical studies guided by this theory is its strong methodological limitation self-imposed by its founder Immanuel Wallerstein. He has repeatedly insisted that his conceptual scheme is no theory at all but a historically limited analysis "embedded in the history 
of the modern world system" (Wallerstein, 2004, 1). This methodological strategy opposes the attempts at explanatory generalizations which are typical for a theory in the strict sense of the word.

Contrary to the global approach of the world system theory to international migration the network theory lays the stress on the variety of micro-social relations and processes which might facilitate, accompany or hinder the cross-border migration flows. The key assumption of the theory is that migrants very much rely on interpersonal ties connecting former, current and future participants in cross-border migration. These "weak ties" are exploited by migrants in their location of origin, in the host countries and in the movement from the former to the latter. The background of the networking is usually the common kinship, friendship as well as the belonging to the same ethnic or religious group. The networks are quite useful since they lower the costs and risks of crossing borders, support the accommodation in the new environment and increase the expected net return of migration (Boyd, 1989).

No doubt, the international migration flows are tangibly motivated, supported or modified by the impact of migrants' networks. They are kind of social capital accumulated and used by the migrants spontaneously or by intention. However, there is sound empirical evidence questioning the stress on the exclusive relevance of networks and networking in cross-border migration. There are macro-social economic, political and cultural factors determining the modalities and the content of the networking. Moreover, once migration corridors have been established the migrants less and less rely on the interpersonal support but more and more on the support of formalized organizations. The reliance on informal networks still remains strong but diminishes substantially in the course of the migrants' adaptation to the new social environment. The weakness of the network analysis notwithstanding it is widely used in migration studies because it captures some relevant dimensions of migration. Critics stress the need to include the explanatory potential of the network approach into broader conceptualizations by respecting the macro-, mezzo- and micro-social dimensions of the cross-border migration simultaneously.

This is the reason why the cognitive and practical relevance of the institutional theory of migration increases together with the legalization and regulation of the crossborder migration flows. There are various types of institutions and institutional arrangements fostering or hindering international migration (Bertocchi and Strozzi, 2008). The inefficient functioning of institutions in the countries of origin of potential migrants is one of the key factors for their dissatisfaction with the local circumstances and for taking the decision to emigrate. During the move of the migrants from the countries of their origin to the host countries of migration various agencies dedicate their activities to serving the needs of the migrants. In some cases the needs include the irregular crossing of borders or trafficking. In the host countries agencies support the migrants' efforts to legalize their stay, to get work permit, to organize the return migration, etc. This booming market attracts a variety of organizations and organization-like networks using legal, semi-legal or illegal methods in their activities. They include various forms of migrants' exploitation and victimization. Under circumstances the treatment of the migrants by these agencies are brutal and non- 
humane to the extreme. The high risk accompanying the crossing of the Mediterranean organized by traffickers using overcrowded old vessels is a typical case in this respect (Mannik, 2016). In order to ameliorate the precarious situations accompanying international migration, humanitarian organizations are active in servicing regular as well as irregular migrants.

All these facts make the institutional theory of cross-border migration a promising building block of the synergetic and probabilistic approach to cross-border migration. In the same time, the theory has serious limitations in its explanatory power. In the average case there are not institutions but individuals who are the major actors getting oriented about the options for migration, taking the decision to migrate, implementing the decision or changing the course and effects of migration activities. Therefore, the comprehensive approach to cross-border migration should do justice to the relevance of the orientations, decisions and actions of individuals for the emergence, reproduction and change of the migration related institutional settings. On the opposite side, there are global and regional macro-social trends shaping the institutional conditions for the orientations, decisions and actions related to the crossborder migration of individuals.

The lacking congruence between the presented conceptual schemes is obvious. They all stress specific components or features of the multidimensional cross-border migration process and focus on mono-linear one-factor determination as a rule. This is not due to the different disciplinary backgrounds of research or to diverging research interests alone. The major reason is the over-complexity of the cross-border migration itself. The need to identify and study particular determination lines urges the researchers to conceptually reduce the over-complexity of the trans-border migration in one way or another. Therefore, the task is to reduce the over-complexity of the cross-border migration in a way allowing comprehensive descriptions, explanations and forecasting. This cannot be achieved by focusing on mono-linear one-factor explanations. The resolution of the task requires intensive analytical and synthetic efforts in order to develop an explanatory strategy which respects the variety of actors, relations and processes characterizing the phenomenon of crossborder migration.

The combination of ideas presented under the headings of the new economics of labor migration, household livelihood strategies and the transnational perspective on migration and social development is a promising step forward in this direction (de Haas, 2010). However, this recent attempt at theoretical synthesis still interprets the impact of cross-border migration on social development in positive terms only. Under various conditions the cross-border migration provokes increase or decrease of the constructive options for orientation, decision and action of individual and collective actors. Therefore, the aggregated effects of the cross-border migration might foster or undermine the capacities of a societal system to actively adapt to its environments (Stocker, 2009). At the micro-level the effects might be the fostering of the creative development of the human capital or its destruction. 
The conclusion of the comparative analysis of theories is that a variety of determinants and determination lines in bringing about and sustaining cross-border migration should be simultaneously taken into account in a differentiated conceptual framework. The above implemented comparative analysis several conceptual schemes makes it possible to formulate basic ideas of the desirable synergetic and probabilistic approach to the cross-border migration:

-The promising approach to the systematic description, explanation and forecasting of international migration should take into account both the sending and receiving side of the migration flows as well as the processes linking both sides of the migration;

-The conceptual scheme(s) necessary for achieving this cognitive aim should cover structures enabling and constraining individual and collective actors to participate in international migration;

-Environmental, economic, political and cultural structures and processes enabling or constraining international migration shape it both in the sending and receiving locations of the migration and in the stages connecting the sending and receiving locations of migration;

-The effects of the international migration flows might be constructive or destructive for the societies sending or receiving migrants or for both of them;

-The outcomes of specific cases of cross-border migration come about under the impact of combinations of various determining factors and this makes the probabilistic approach to international migration the meaningful alternative to the onedimensional deterministic explanatory schemes;

-The preference towards the synergetic and probabilistic approach is dictated by both its cognitive advantages and by its potentials to guide efficient policies for managing international migration.

\section{Linking Determining Factors, Processes and Effects of the Cross-border Migration}

The starting point in the development of the synergetic and probabilistic approach to international migration is the identification of major stages in the process together with the links between them. The first stage is marked by the frustrations of potential migrants accumulated in their home country. The difficult or unbearable conditions might be brought about by natural events like earthquakes (Armenia in 1988) or famines (Somalia in 2012) as well as by man-made causes like protracted poverty or deep economic crisis, ethnic and religious intolerance, foreign interventions, riots and civil wars (Iraq after 2003, Syria after 2011). The typical outcome is the growing motivation to take the risks of cross-border migration in order to save or to develop the human capital under more favorable conditions. In some cases the pressure of violence, the acute economic crisis or other circumstances do not leave time for considerations since it is existentially important to leave the country as soon as possible. If there are options for making a choice, then the first steps in the process include the selection of desirable destination(s) and the decisions about the legal 
requirements (visa issue, insurances, etc.) to reach and enter it. The organizational matters to be dealt with concern the funding of the trip and the modalities of travelling. Irregular border crossings and transportation are always options although risky ones as a rule. Nevertheless, precarious conditions might make them the only available modalities of migration.

Once the new destination of desirable, acceptable or just possible future residence has been reached, the next task on the agenda of the cross-border migrants is the adaptation to the new economic, political and cultural environments. The key issues at this stage of migration concern the asylum permit, residence permit and the work permit. In the course of time the links with the country of origin, the sending of remittances, and possibly the return migration might take the lead. In the case that the movement through these stages of the cross-border migration becomes mass phenomenon, it unavoidably has tangible impacts on the economic, political and cultural life of the source countries of migration and the host countries. Figure 1 presents the so outlined major stages of the cross-border migration and its effects:

Figure 1: Basic scheme of out-migration, immigration and return migration

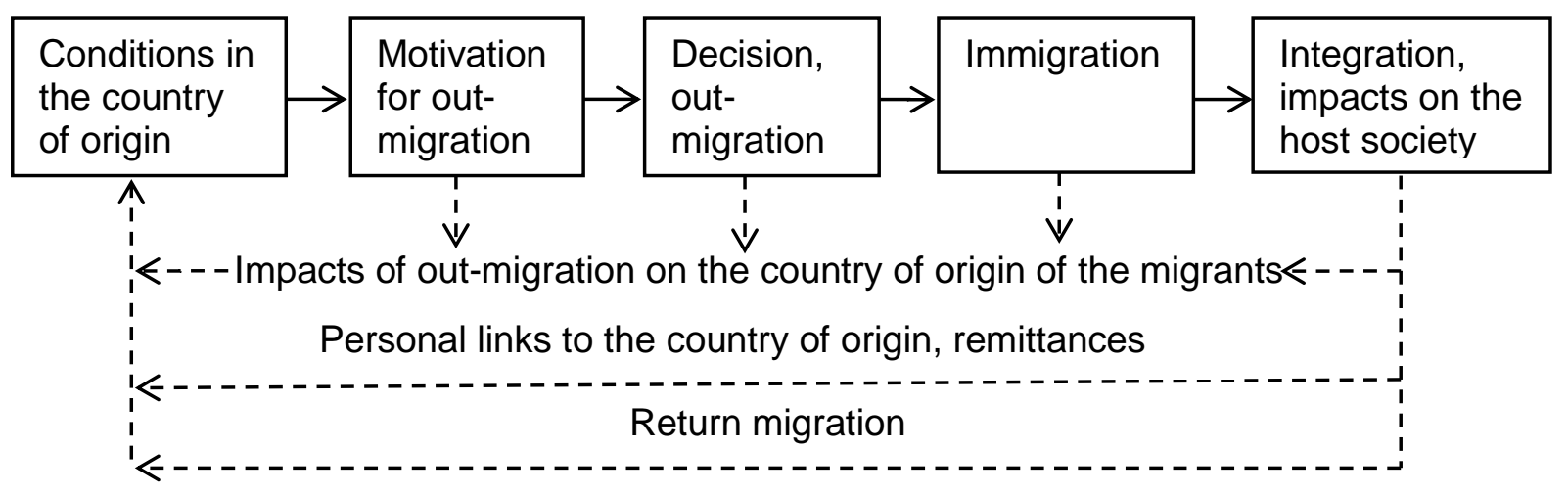

Source: The author

The crucial task in the development of the synergetic and probabilistic approach to cross-border migration is the step-by-step elaboration on the above simplified descriptive scheme. The aim is to build up a differentiated conceptual framework allowing systematic operationalization, empirical testing of explanations as well as procedures of forecasting. The promising way for achieving this result is the separation of three major components of the intended conceptual framework and the elaboration on each of them in details.

The first component of the conceptual framework covers the accumulation of dissatisfactions with the conditions in the country of origin by potential cross-border migrants. In some cases the dissatisfaction might have separate and clearly identifiable economic, political, cultural or environmental reasons. Nevertheless, in the public mind they are typically generalized in the notion of generally inacceptable 
living conditions. The mass out-migration from Bosnia and Herzegovina during the first half of the nineties or currently from Syria, Iraq or Afghanistan is a vivid illustration of the mixture of factors determining the final decision in favor of the cross-border migration (Poirier, 1998; Bauer, 2014).

The broad range of possible determining factors of out-migration is specified in two directions for the purposes of the systematic collection and processing of information concerning the "push factors" of migration. The first direction is the differentiation of parameters of the potential environmental, economic, political and cultural determinants of the need satisfaction/dissatisfaction. The second direction follows the differentiation of needs relevant for the decision to out-migrate or to stay in the country of origin. This specification of needs and need satisfaction/dissatisfaction tentatively follows Abraham Maslow's idea of the pyramid of needs. The needs and needs satisfactions/dissatisfactions in the fundament of the pyramid are related to issues of existentially relevant environmental risks and parameters of material consumption. The advanced civilizational needs on the top of the pyramid are represented by the desire for open social space for professional development and realization as well as by the concerns about the children's future. In-between on the scale the indicators for need satisfactions/dissatisfactions are located. They are related to the quality of the settlements' infrastructure, the quality of the health care in the country, its economic and political stability, the quality of the educational system and the level of interethnic and inter-religious tolerance.

These generalized indicators can be used in the first efforts to establish potentials for out-migration. A five to ten point scale might inform about the level of satisfaction/dissatisfaction with the quality of the local educational system, for instance. The indicators can be further specified and operationalized for the purposes of the collection and processing of detailed empirical information. This is the condition for efficient testing of hypotheses concerning the level of needs satisfaction/dissatisfaction of the potential cross-border migrants in their country of origin. Complex research questions might be formulated in relation to these parameters: What kind of impacts has the perception of local environmental risks on the assessment of the local quality of life and on the related decision to stay in the country of origin or to out-migrate? What impacts has the perception of inter-ethnic tolerance or intolerance on the satisfaction/dissatisfaction with the quality of life in the country of origin as well as on the related decision to stay in the country or to outmigrate? Some indicators used in the formulation of such questions and in the search for precise description and explanation of the ongoing processes are differentiated in Figure 2. It provides the conceptual framework for answering questions about the conditions under which the accumulation of need dissatisfactions might lead to orientations, decisions and actions for out-migration from the country of origin or not. The specific research tasks or the needs of migration management might require the introduction and application of more differentiated indicators. They could focus on the level of inequality in the distribution of incomes and wealth or on the deficiencies in the legal system in the country of origin of international migrants. Other questions might focus on the information the would-be migrants have about the economic, 
political or cultural situation in the desirable destination of migration. These specifications of the intensity of needs satisfaction/dissatisfaction makes it possible to explain the motives for out-migration more precisely (Carr, 2010: 85-170). The wide range of fields to be covered by information sources is presented in Figure 2:

\section{Figure 2: Accumulation of potentials for out-migration (,push factors“)}

\section{Determining factors}
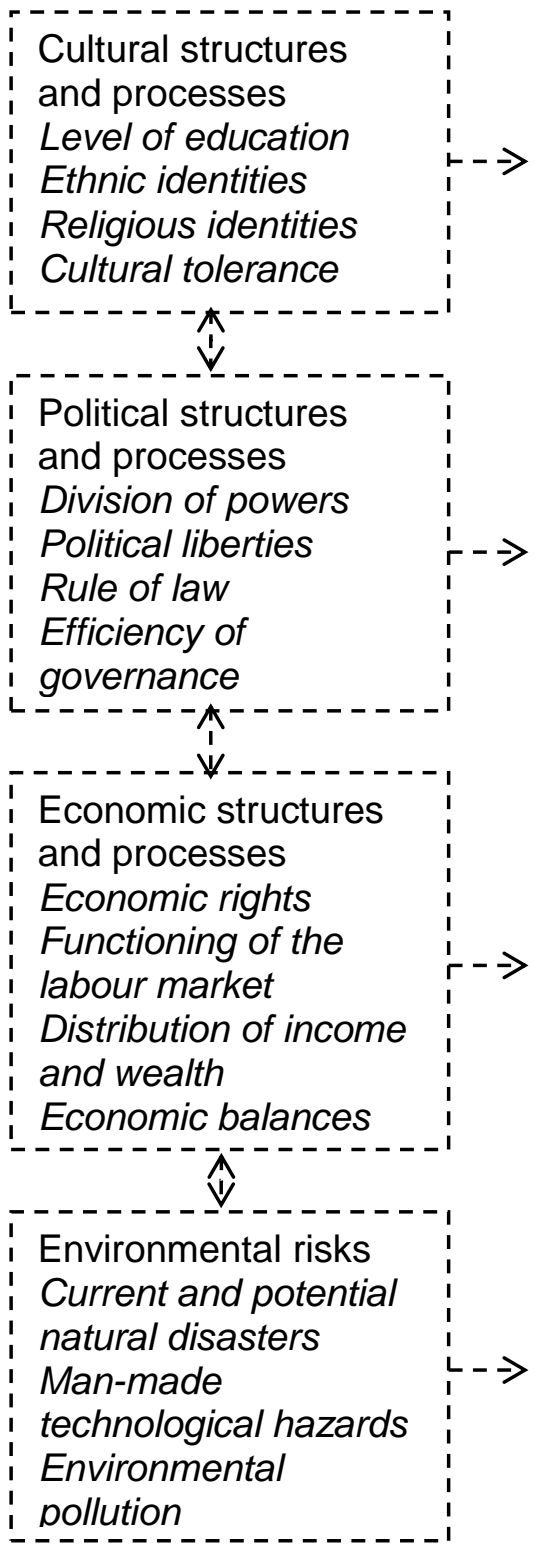

\section{Needs Reasons for dissatisfaction}

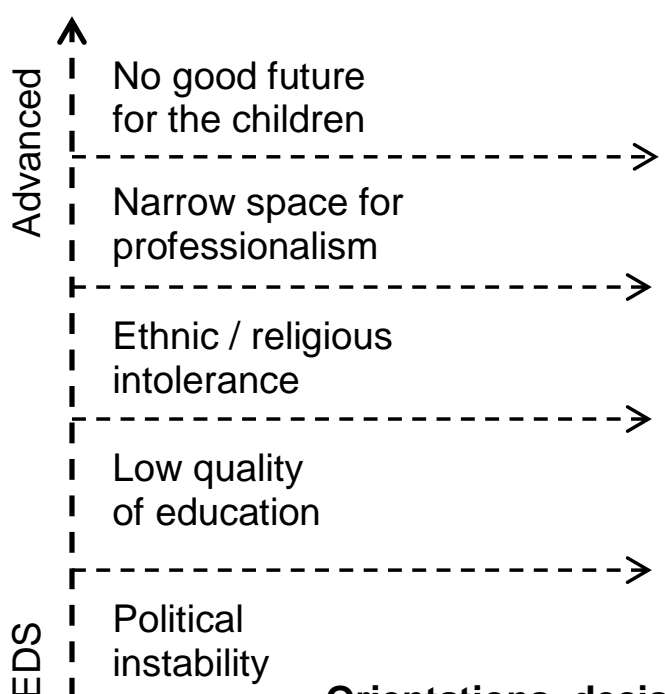

Orientations, decisions, migration

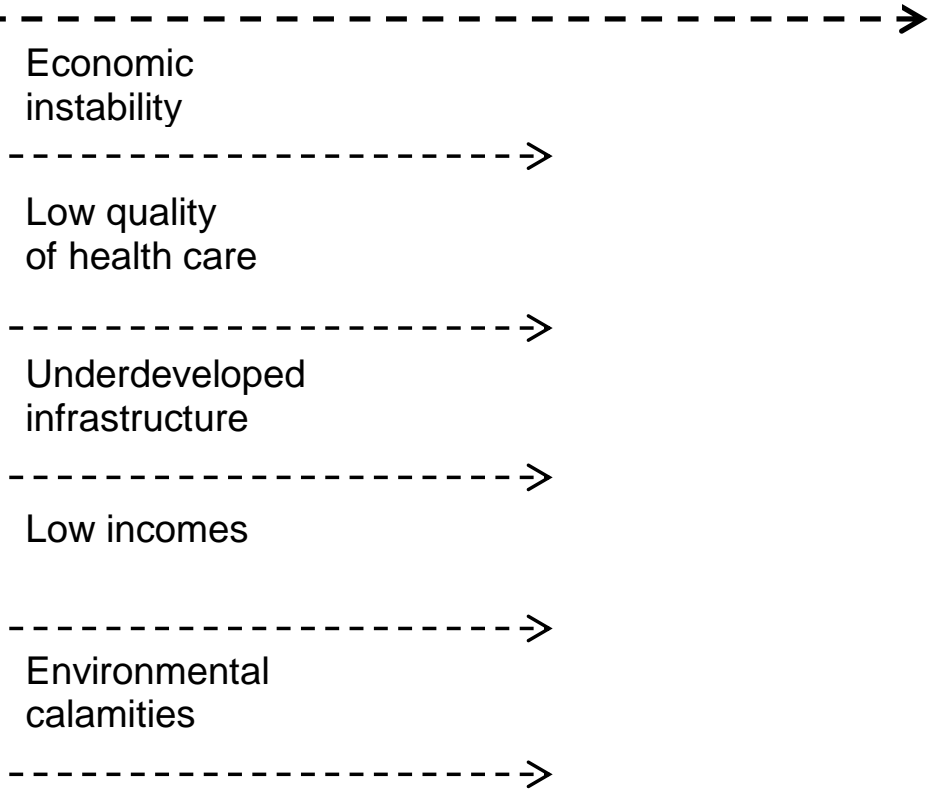

Source: The author

The differentiated approach to the factors determining the probability of out-migration opens the way to the selection and use of a variety of research tools in field studies. The tools might include analysis of often unreliable statistical information, analysis of governmental and scientific documents, elaboration on results of public opinion polls, in-depth interviews with experts, in-depth interviews with potential migrants and with returnees from international migration, Delphi sessions with experts on the prospects 
of out-migration as well as on the prospects of return and circular migration, etc. Some theoretical and methodological inspirations for the studies may be received from ideas of the neoclassical theory of international migration, world systems theory, the theory of the dual labor market or from studies carried out following these ideas.

The decisions taken by individuals or possibly by collectives (as supposed by the new economics of migration) for joining the migration flows put the crossing of the distance between the country of origin and the country of destination high on the agenda. The resolution of the task implies the overcoming of four major legal, organizational and territorial barriers. The first one concerns the departure from the country of origin. For many out-migrants this is a minor issue. However, there are still situations in which the border control of the state of origin requires valid visas, insurances and other documents in order to allow the citizens to leave the country. Financial, bureaucratic or political obstacles might make the would-be out-migrants inventive in the search for options to cross the border in an irregular way. There are persons and organization-like networks which have the expertise and organizational capacities to supply the would-be migrants with forged documents or to arrange other irregular ways of crossing the border (Triandafyllidou and Maroukis, 2012).

Legal, semi-legal or illegal organizations or organization-like actors are involved in supporting the migrants to overcome the distance between their country of origin and the country of destination. Technical or organizational problems could rarely hinder the travelling of migrants because of the well-developed means of international transportation. The costs are relatively low as well. Nevertheless, the mobilization of support from relatives, friends or settlement communities to the would-be migrants is a common practice in the low income countries. Irregular travelling is often the only or the preferred option for poor migrants too. The diverse practices of their travelling offer a broad intellectual space for a variety of hypotheses and research questions. Some of them concern the options for orientation, decision and actions of the migrants themselves while others focus on the organizational conditions and the supporting actors involved in the move of migrants. The study of the circumstances of their legal, half-legal or illegal move to the country of destination requires a lot of inventiveness in the collecting of empirical information. Soft methods of participant observations or improvised interviews are often preferable or only possible research instruments. The network analysis usually provides valuable primary information.

The next step in the international migration is the crossing of the border of the country of destination. The crossing is not problematic for legally well prepared immigrants. They are expected to possess the documents required for the purpose. However, in a lot of cases all or some of these documents are not available or the migrants possess - intentionally or not - no documents at all. Consequently, the search for irregular ways to enter the country of destination is rather intensive. The massive smuggling of immigrants through European borders or the tunnels under the fence dividing the United States and Mexico are vivid examples of the problem and the variety of practiced irregular solutions to it (Kyle, 2011). 
The stages of the movement from the country of origin to the establishment of the status of the migrant in the country of immigration are schematically presented in Figure 3. The differentiated operationalization of the presented concepts might continue in order to refer to the specifics of local situations. The collection and processing of empirical information serves the testing of explanatory hypotheses about the frequency or the effects of forging travel documents or of smuggling crossborder migrants into the country of their destination. The primary information needed for the adequate description, explanation and forecasting of the above processes is collected by applying soft methods in most cases. Ideas of the network analysis and the institutional theory of migration are often used in this research context too.

\section{Figure 3: Overcoming barriers in cross-border migration}

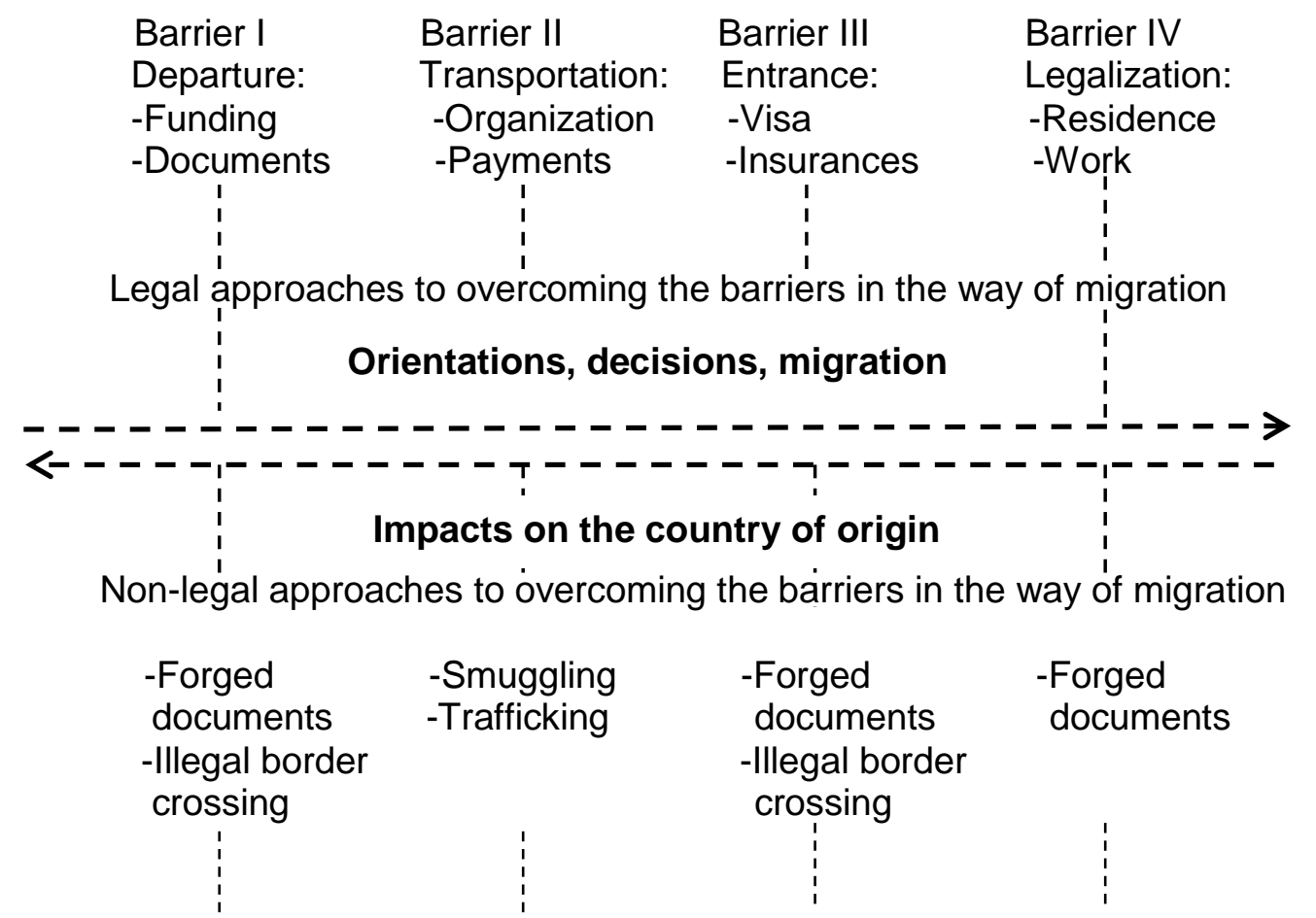

Source: The author

Once having entered the host country thousands of irregular migrants are facing the threat of deportation. In democratic societies the procedure takes long and it is not always efficient. The immigrants who remain without residence and work permit usually find a niche in the shadow economy. They earn their living without legal protection and under permanent stress. The state institutions in the host countries have difficult tasks in managing the problem. Civil society organizations and various networks are involved in the process by providing migrants with basic necessities and protecting their human rights (Bansak, 2016).

The expectations of the cross-border migrants concerning the conditions in the host country might be confirmed entirely, partly or not at all. Given the accumulated frustrations in the country of origin, in many individual cases the feelings of achievement already predominate when the migrants manage to legalize their stay 
and to secure basic income in the host country. The feelings of satisfaction might be strengthened by the successful family reunion and by the inclusion of the family in the social support schemes. When immigrants have obtained a good or very good occupational status and have promising occupational perspectives the intensity of satisfaction with the outcomes of the cross-border migration is particularly high.

The cases in which the disappointment is predominant follow the failed or only partly successful efforts to adapt to the new economic, political and cultural environment. The reasons for the dissatisfaction vary. Most often immigrants start the adaptation from lower occupational positions than their education might suggest. Some immigrants have to experience this discrepancy for long thus going through occupational degradation. The immigrants who experience degradation of their need satisfaction in the host country is more prone to return back to the country of origin than the immigrants who have reached a satisfactory balance between their expectations and achievements in the adaptation. The "satisfactory balance" is a tricky definition, though. Many immigrants tend to understand the low level of need satisfaction in the host country as an achievement after comparing with the parameters of the lower need satisfaction in their countries of origin (Hagendoorn, Veenman and Vollenbergh, 2003). Researchers have identified alarming outcomes of the accumulated dissatisfactions too. The most problematic one is the ideological and political radicalization of immigrants and the potential transformation of their dissatisfaction into extremist activities, terrorism including (Pilati, 2016).

The achievements and the failures in the economic, political and cultural integration of migrants in the host country have long-term implications for its own structures and processes. The constructive implications start from the rejuvenation of the labor force and reach the mutual enrichment of cultures and human relationships. However, the degradation of some immigrants into criminals, homeless, drug addicts, long-term receivers of social benefits or terror-prone extremists has also implications for the integration and the developmental prospects of the host society (Lazaridis, 2015). The stay of immigrants in the host country has implications for their country of origin too. They range from the decline of the pressure on the local labor market due to the emigration and the positive effects of the remittances received by relatives and friends on their quality of life. But emigration deprives societies from human capital they need for their development. Remittances are also mixed blessing since they are rarely invested in productive activities. They cause and support the expectation that somebody else has to provide for the necessities of life to people remaining in the country of origin of migrants. Remittances also strengthen the desire of the most capable individuals to go abroad in order to share the affluence there. As a result, societies massively sending emigrants are threatened to reach the point of a critical reduction of the active segment of their labor force and the depopulation of whole regions. These processes in the host country of trans-border migrants and the effects of their immigration are presented in Figure 4: 
Figure 4: „Pull factors“ and impacts of the cross-border migration

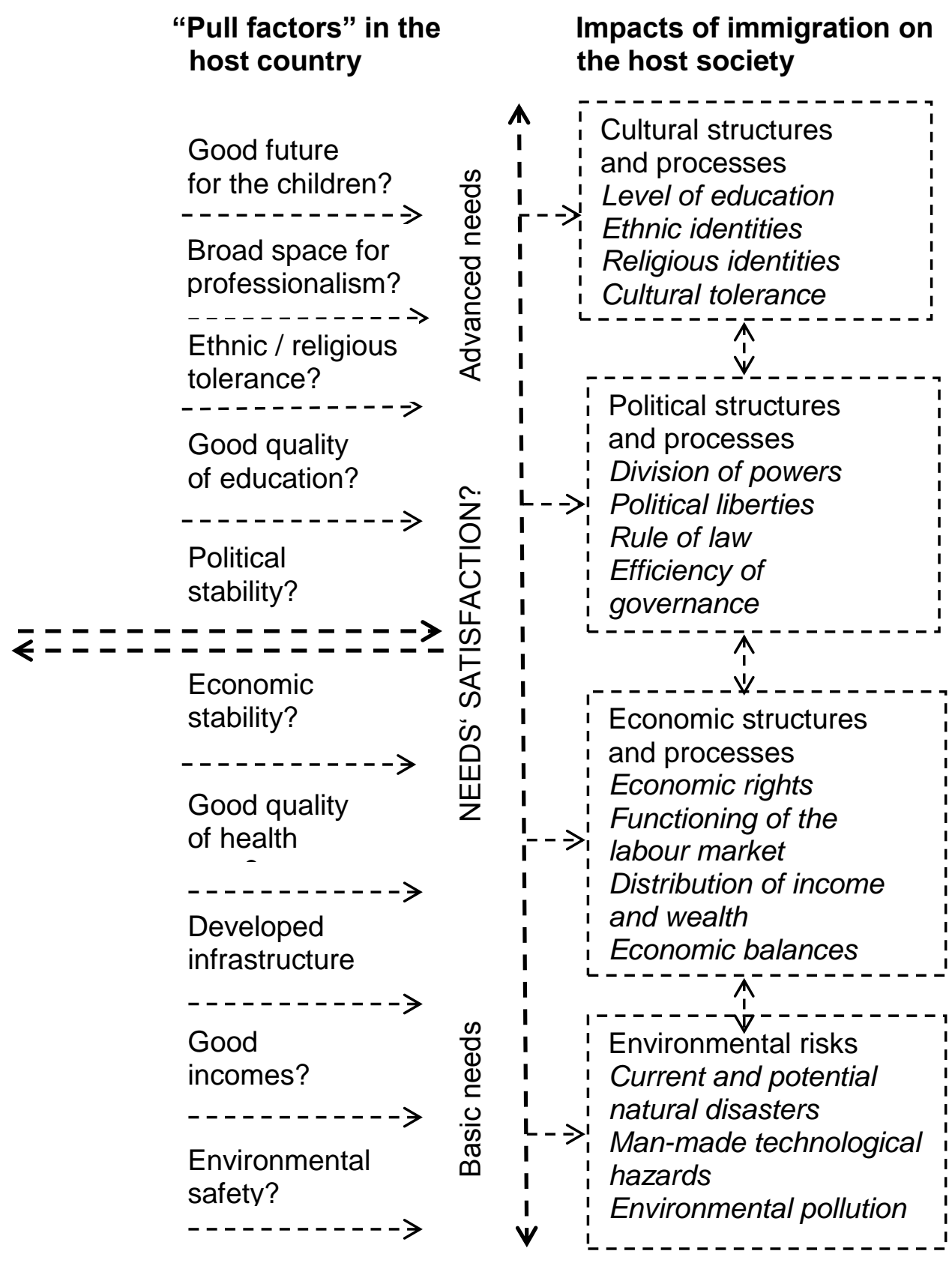

Source: The author

The strategy of using mixed methods is most promising in the study on the effects of cross-border migration on host societies. Their statistical offices offer reliable information in most cases but the relevant statistical indicators are so far not differentiated and detailed enough. Governmental documents and scientific studies ordered by governments are usually quite informative. In-depth interviews with experts in the fields of the economic, political and cultural integration of immigrants are valuable sources of research information. In-depth interviews with immigrants focusing on their adaptation to the new economic, political and social environment as well as on their networks are crucially important for the adequate descriptions and explanation of achievements and handicaps in the integration process. Interviews with control groups of citizens of the host societies provide the information about their perception and assessment of the effects and prospects of the immigration. Delphi 
sessions with local experts are helpful for understanding trends in the immigration flows and effects of immigration policies. Theoretical ideas about human capital and social capital development can effectively guide these empirical studies.

The above presented conceptual parts have to be put together into a comprehensive conceptual framework needed for systematic descriptions and explanations of the cross-border migration. The conceptual synthesis is expected to cover all major components, stages and processes characterizing the cross-border migration. This is the final stage in the development of the synergetic and probabilistic research and management approach to the cross-border migration (Figure 5):

\section{Figure 5: Conceptual framework for a synergetic and probabilistic approach to cross-border migration}

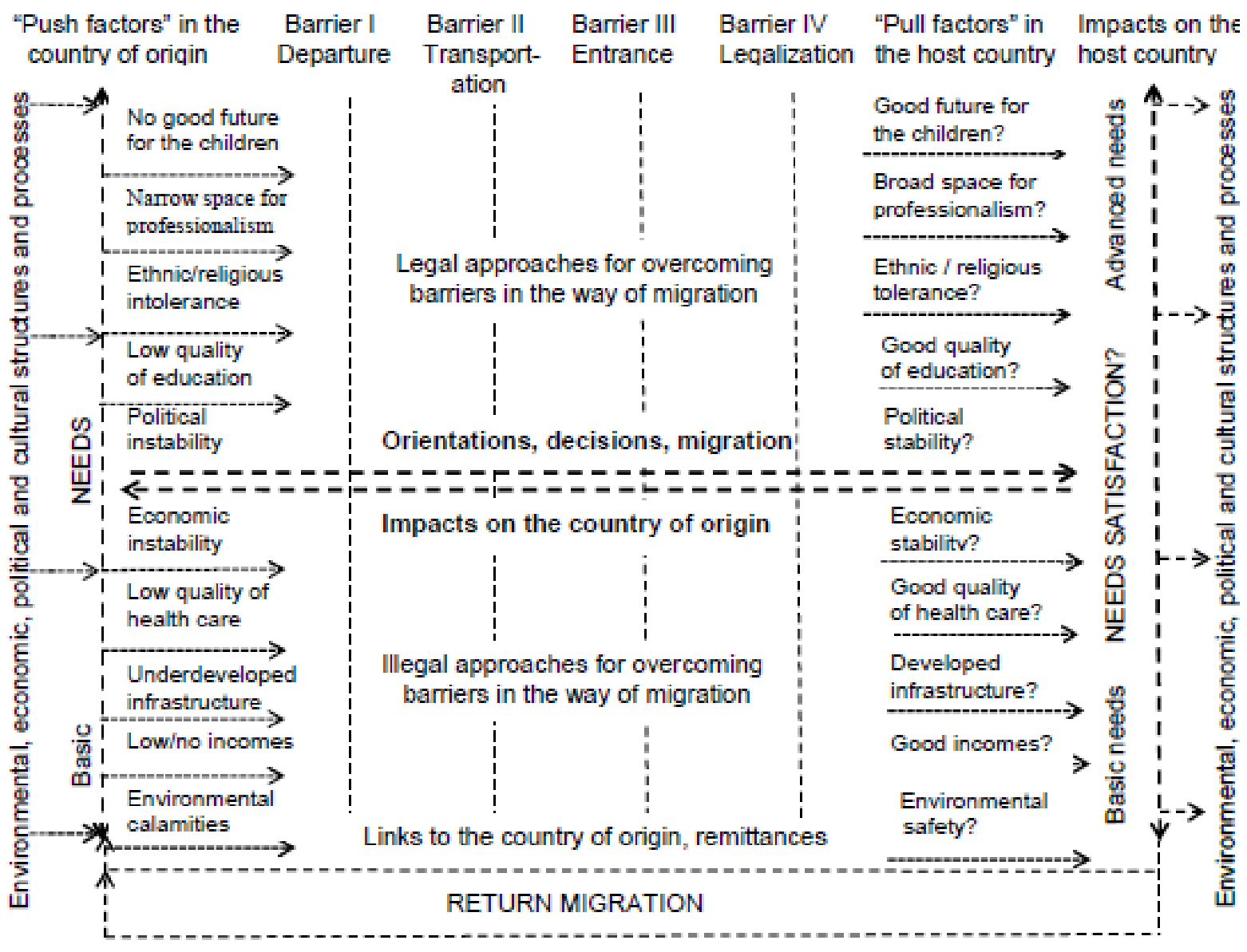

\section{Source: The author}

The above presented strategy for the systematic, probabilistic and multi-dimensional research approach to the cross-border migration is balanced since it does not give special priority to any particular determining factor, to any actor, to any process or to any effect of the migration. This should not imply that the predominant relevance of specific factors, actors, processes or effects could not be put under special scrutiny or placed in the very center of descriptive, explanatory or prognostic procedures. However, when taking a specific component or parameter of the cross-border 
migration for detailed study, the vision about its place and role in broader interactions of migration remains clearly defined in the full-fledged conceptual framework. This clarity prevents distortions in the description and the more so in the efforts to reach precise descriptions and explanations of the factors and the effects of determination lines. Varieties of forecasting might be also well embedded in the systematic information about available conditions, options and probabilities for future developments.

The synergetic and probabilistic approach to international migration has been developed for facilitating full-scale studies on migration from its beginnings in the countries of origin till the integration of migrants in the host countries (Genov and Savvidis, 2011). Unfortunately, this type of full-scale studies is still rare due to financial and organizational constraints. Nevertheless, a variety of environmental, economic, political and cultural structures and processes related to cross-border migration might be included in the studies focused on particular stages, actors and processes of the migration. Gender differences can be taken into account at various contexts. Precise definitions of the temporal and space characteristics of the migration help focusing research on details of the ongoing processes without losing the view on the broader context. The specifics of the intra-national, cross-border or transnational processes can be systematically included in the descriptions and explanations (Singer, 2011). Given the available experience with the utilization of the world systems theory in the study of the cross-border migration, one might expect productive future linkages of the synergetic and probabilistic studies on migration with the prospective research on global trends (Genov, 2016). Still another valuable characteristic of the above presented conceptual framework is its potential for systematic conceptual orientation of policies focusing on the management of international migration.

\section{Managing Cross-border Migration}

The experts relying on diverging and often contradictory theoretical ideas recommend diverging strategies for managing emigration and immigration to policymakers. This lack of congruence is matter of serious concerns on the part of researchers and policy-makers alike (Geiger and Pecoud, 2010; United Nations, 2013). It is widely recognized that decisive steps are needed in order to integrate migration theories and consequently the policies for coping with the cross-border migration. In the terms of Idealpolitik the major aim of the policies for managing international migration would be to make migration a triple-win process for the countries sending and receiving migrants as well as for the migrants themselves. At present there is no policy which would really match such idealized expectations. The above presented explanatory strategy is developed with the intention to orient comprehensive policies which might achieve positive or optimal results by using the conceptual framework on Figure 5 for orientation of research as well as of the management of cross-border migration. The framework suggests options for improvement of the situation in the countries of origin of migrants in order to reduce 
the intensity of the motivation to migrate; for well-organized struggle against criminal networks immensely profiting from the smuggling and trafficking of migrants; and for their efficient integration in the host societies. The conceptual scheme covering all stages and dimensions of the cross-border migration opens the prospects for purposefully organizing circular migration which is currently regarded as the most desirable outcome of the migration management (Triandafyllidou, 2013).

The potential for return migration is a special component in this management strategy. Intergovernmental agreements may facilitate the selection and training of potential migrants for specific occupations and for teaching them language skills already in the countries of origin. It would be productive to accompany these activities with legal regulations for re-admission of migrants and for supporting their re-integration in the society of origin. The host societies might support these measures financially in order to invite the qualified migrants in times of labor shortages under the conditions of economic boom. The legal and institutional system in the countries receiving migrants could be also prepared to send the migrants back in periods of economic recession by using elaborated mechanisms of flexible labor contracts.

The most ambitious policies would focus on the connection between migration and development by improving the productive and service infrastructure in the countries sending migrants as well as by searching for the most efficient use of their remittances (International Migration and Remittances, 2013). The support for reintegration of returnees from cross-border migration is another attractive option for migration management. Some migrants would return back to their country of origin with accumulated financial capital, with new experience in the work and outside of the work (human capital) as well as with established networks in the host country of migration (social capital). These types of capital might be well used in the country of migrants' origin provided the local legislation and the institutional practices there would be prepared to absorb them. In this way the negative effects of the brain-drain might be reduced if not fully eliminated (EMN, 2011).

The options for rationalization of the domestic and international labor markets are conceptually elaborated in the two pillars of needs satisfaction on the left and the right hand sides of Figure 5 as well as in the conceptual links between the two pillars. Bilateral and multilateral agreements would relieve the country sending migrants from the pressure of the idle labor force by offering the vents of the employment abroad. Bilateral agreements might facilitate the economic advancement and political stabilization of the country sending migrants. If properly conceived and implemented, these policies can weaken the pressure to migrate and improve the conditions for migrants' returning back to their country of origin. The well-organized circular migration would relieve the countries receiving migrants from the complicated economic, political and cultural issues related to the migrants' permanent settlement there. In the ideal case the circular migration makes the links between the countries sending and receiving migrants efficient, safer and politically acceptable for the electorate. This desirable effect can be achieved by introducing multiple entry visas, transferable welfare benefits, by supported transportation, etc. These regulations 
would protect the migrants' human rights by making the semi-legal and illegal activities in these areas less attractive.

As promising the circular migration and the related policies might seem the experience is not particularly encouraging in this respect. State strategies focusing on circular labor migration have already failed due to the decision of migrants not to return back to their countries of origin. The policies of circular migration are an attractive target for political interpretations since they might be easily presented as problematic in various respects. The politicians from the opposition parties prefer to argue that the remittances sent to the countries of origin are settling the bill of the desirable win-win situation. This type of argumentation and the related policies provoke uncertainties among researchers and administrators concerning the prospects of the circular migration.

The stress on the multiple advantages of the well-organized circular migration should not neglect the complexity of the related problems and the danger of failing policies (Wickramasekara, 2011; Solé et al., 2016). Therefore, it would be unrealistic to expect a predominance of circular migration. The majority of the cross-border migrants will continue to come from failed or inefficiently functioning states weakened by wars, corrupt governments or natural disasters. Migrants fleeing from such circumstances typically move as a disorganized stream and aim at permanent settlement in the better-off host countries. Circular migration cannot be well organized under such conditions of mass suffering and chaotic migration movements. The options for rational management of mass cross-border migration of this type are limited indeed. Nevertheless, these options have to be carefully considered in order to avoid the destructive side-effects of both the assimilationist and multiculturalist management strategies in the host countries of international migration. Both strategies have been tested under various conditions and proved to be fundamentally questionable in most cases. This is the context in which the explanatory scheme on Figure 5 might be specially regarded as the promising orientation for preparation and implementation of policies with win-win-win effects in the management of international migration.

\section{Conclusions}

The suggested multi-dimensional and probabilistic research strategy takes both the general and locally-specific parameters of the cross-border migration into account. This is a task which has to be dealt with by experts on the basis of the outcomes of research in each specific case. Under this condition the outcomes of research would be the reliable cognitive basis for policies designed and implemented by professionalized individuals, groups and institutions. The investments needed for high-quality research on the cross-border migration as well as for its high-quality management have a very high potential return. To the contrary, the neglected or nonprofessionally carried out research and management of international migration strike back on the countries sending and receiving migrants as well as on migrants 
themselves. The constructive or destructive effects of the policies aiming at the management of international migration tend to multiply together with the intensification of the migration flows and the rising numbers of international migrants. The simple rule in such situations reads: It is better to invest relatively modest financial means and organizational efforts in advance in high-quality research and policy design than to try to mitigate the destructive effects of the neglected research and management of international migration flows tomorrow. The relevance of this rule becomes clear if the available contradictory experiences would be considered. International migration might play the role of a powerful factor for economic and social development for both the countries sending and receiving migrants. But in many particular cases the international migration has already had predominantly destructive effects in both directions. The above suggested comprehensive conceptual framework is intended to support policies facilitating the potential constructive effects and reducing the potential destructive effects of the cross-border migration.

\section{Reference}

Abreu, A. (2012). 'The New Economics of Labor Migration: Beware of Neoclassical Bearing Gifts'. Forum for Social Economics 41(1): 46-67. http://dx.doi.org/10.1007/s12143-010-9077-2

Adukule, W. (2016). Flucht: Was Afrikaner außer Landes treibt. Berlin: Das neue Berlin.

Bansak, C. (2016). Legalizing Undocumented Migrants: While Legalization Benefits Most Undocumented Migrants, Deciding How to Regularize Them is Challenging. Bonn: IZA.

Bauer, W. (2014). Über das Meer: Mit Syrern auf die Flucht nach Europe. Berlin: Suhrkamp.

Bauman, Z. (2016). Strangers at Our Door. Cambridge and Oxford: Polity

Bertocchi, G. and Chiara S. (2008). 'International Migration and the Role of Institutions'. Public Choice 137: 81-132. http://dx.doi.org/10.1007/s11127-008-9314-x

Bodvarsson, Ö.B. and Van den Berg, H. (2013) The Economics of Immigration : Theory and Policy. New York: Springer, DOI 10.1007/978-1-4614-2116-0_2.

Borjas, G. J. (1989). 'Economic Theory and International Migration'. International Migration Review, 23 (3): 457-485. http://dx.doi.org/10.2307/2546424

Bossong, R. and Carrapiço, H. (Eds.) (2016). EU Borders and Shifting Internal Security. Dordrecht etc.: Springer. http://dx.doi.org/10.1007/978-3-319-17560-7

Boyd, M. (1989).'Family and Personal Networks in International Migration: Recent Developments and New Agendas'. International Migration Review, 23 (3): 638-670. http://dx.doi.org/10.2307/2546433

Brettel, C. B. and Holifield. J.F. (2011). 'Migration Theory: Talking across Disciplines'. In: Brettel, Caroline B. and James F. Holifield. eds. Migration Theory: Talking Across Disciplines, $3^{\text {rd }}$ edition, New York etc.: Routledge, pp. 1-30.

Carr, S. C. (Ed.) (2010). The Psychology of Global Mobility. New York and London: Springer. http://dx.doi.org/10.1007/978-1-4419-6208-9

Castles,S; de Haas, H. and Miller, M.J. (2014). The Age of Migration. International Population Movements in the Modern World. Basingstoke Hants: Palgrave Macmillan, 5th ed. 
EMN - European Migration Network (2011). Temporary and Circular Migration: Empirical Evidence, Current Policy Practice and Future Options in EU Member States. Brussels: European Migration Network.

Eurostat (2016) Migrant Integration Statistics - Employment. http://ec.europa.eu/eurostat/statisticsexplained/index.php/Migrant_integration_statistics_-_employment\#Youth_unemployment (Retrieved 24.06.2016)

Favell, A. (2011). 'Rebooting Migration Theory. Interdisciplinarity, Globality and Postdisciplinarity in Migration Studies'. In: Brettell, C.B. and Hollifield,J.F. (Eds.) Migration Theory. Talking Across Disciplines, $3^{\text {rd }}$ ed. New York etc.: Routledge, pp. 259-278.

Geiger, M. and Pécoud,A. (Eds.) (2010). The Politics of International Migration Management. New York: Palgrave Macmillan. http://dx.doi.org/10.1057/9780230294882

Genov, N. (2015). 'Challenges of Individualization'. International Social Science Journal, N 213-214, pp. 197-209.

Genov, N. (2016) 'Competing Sociological Diagnoses of Contemporary Times: Potentials of the RISU Conceptual Framework'. International Journal of Social Science Studies, Vol. 4, No. 1; January, pp.86-98.

Genov, N. and Savvidis, T. (Eds.) (2011). Transboundary Migration in the Post-Soviet Space: Three Comparative Case Studies. Frankfurt/M., etc.: Peter Lang. http://dx.doi.org/10.3726/978-3-65300862-3

de Haas, H. (2010). 'Migration and Development: A Theoretical Perspective'. International Migration Review, 44 (1): 227-264. http://dx.doi.org/10.1111/j.1747-7379.2009.00804.x

Hagendoorn, L.; Veenman, J. and Vollenbergh, W. (Eds.) (2003). Integrating Immigrants in the Netherlands: Cultural versus Socio-economic Integration. Aldershot etc.: Ashgate.

Hatton, T. J. and Williamson, J.G. (2005). Global Migration and World Economy: Two Centuries of Policy and Performance. Cambridge, MA: MIT Press.

Hofmann, D. (Ed.) (2011). Headhunter: Blick hinter die Kulissen einer verschwiegenen Branche. Wiesbaden: Gabler. http://dx.doi.org/10.1007/978-3-8349-6448-9

International Migration and Remittances (2013). International Migration. Special Isssue, 51/ Supplement $\mathrm{s} 1$.

Jansen, Y.; Celikates, R. Joost de Bloois, J. (Eds.) (2015). The Irregularization of Migration in Contemporary Europe: Detention, Deportation, Drowning. London etc.: Rowman \& Littlefield.

Kingsley, P. (2016) The New Odyssey: The Story of Europe's Refugee Crisis. London: Guardian Faber.

Kyle, D. and Koslovski, R. (Eds.) (2011). Global Human Smuggling: Comparative Perspectives. Baltimore: The John Hopkins University Press.

Lazaridis, G. (2016). International Migration into Europe: From Subjects to Abjects. Houndmils and New York: Palgrave Macmillan.

Luft, S. (2016). Die Flüchtlingskrise: Ursachen, Konflikte, Folgen. München: C.H.Beck. http://dx.doi.org/10.17104/9783406690730

Mannik, Linda (2016). Migration by Boat: Discourses of Trauma, Exclusion and Survival. Oxford and New York: Berghahn Books.

Maslow, A. (2006). Motivation and Personality. $3^{\text {rd }}$ ed. New York, etc.: Longman.

Massey, D. S. and Espinosa, K.E. (1997). "What's Driving Mexico-US Migration? A Theoretical, Empirical and Policy Analysis." American Journal of Sociology, 102(4): 939-999. http://dx.doi.org/10.1086/231037 
Massey, D. S.; Arango, J.; Hug, C.; Kouaouci, A.; Pellegrino, A. and Taylor, J.E. (2005). Worlds in Motion: Understanding International Migration at the End of the Millennium. Oxford: Clarendon Press.

Pilati, K. (2016). Migrants' Political Participation in Exclisionary Context: From Subcultures to Radicalization. Basingstock, Hampshire: Palgrave Macmillan. http://dx.doi.org/10.1007/978-1137-55360-7

Poirier, C. R. (1998). The Breakup of Yugoslavia and the War in Bosnia. Westport (Conn.): Greenwood Press.

Saint-Paul, G. (1996). Dual Labor Markets: A Macroeconomic Perspective. Cambridge, Mass.: MIT Press.

Scelatto, G. and Stephan, P. (2012). Foreign Born Scientists: Mobility Patterns for Sixteen Countries. Cambridge, MA: National Bureau of Economic Research. Available at: 2012_5_1_Stephan_Foreign-born-scientists.pdf (Retrieved 04.05.2016).

Singer, A. (2008). 'Twenty-First-Century Gateways: An Introduction'. In: Singer, Audrey et al., eds. Twenty-First Century Gateways: Immigrant Incorporation in Suburban America. Washington, D.C.: Brookings Institution Press, pp. 3-30.

Solé, C.; Parella, S.; Martí, T. S. and Nita, S. (Eds.) (2016). Impact of Circular Migration on Human, Political and Civil Rights: A Global Perspective. Cham ; s.I. : Springer International Publishing. DOI: 10.1007/978-3-319-28896-3.

Stocker, S. (Ed.) (2009). European Social Watch Report 2009: Migrants in Europe as Development Actors. Between Hope and Vulnerability. Bruxelles: Eurostep. Available at: http://www.socialwatch.eu/2009/home.html (Retrieved 22.10. 2015).

Triandafyllidou, A. and Maroukis, T. (2012). Migrant Smuggling: Irregular Migration from Asia and Africa to Europe. Basingstoke, UK and New York: Palgrave Mackmillan. http://dx.doi.org/10.1057/9780230369917

Triandafyllidou, A. (Ed.) (2013). Circular Migration between Europe and Its Neighbourhood: Choice or Necessity? Oxford: Oxford University Press.

United Nations (2013). International Migration Policies 2013. New York: United Nations. https://www.un.org/en/development/desa/population/publications/policy/international-migrationpolicies-2013.shtml (Retrieved 18.01.2016).

Waldinger, R. D. (2015). The Cross-border Connection: Immigrants, Emigrants and Their Homelands. Cambridge, Mass.: Harvard University Press. http://dx.doi.org/10.4159/harvard.9780674736283

Wallerstein, I. (2004). World-systems Analysis : An Introduction. Durham: Duke University Press.

Wickramasekara, P. (2011). Circular Migration: A Triple Win or a Dead End. Geneva: ILO

http://www.google.com/webhp?nord=1\#nord=1\&q=Circular+Migration\%3A+A+Triple+Win+or+a+Dead +End (Retrieved 26. 11.2015).

Yomogida, M. and Laixun, Z. (2010). 'Two-Way Outsourcing, International Migration, and Wage Inequality'. Southern Economic Journal, 77(1): 161-180. http://dx.doi.org/10.4284/sej.2010.77.1.161 